\title{
Origiginal Arrtichle
}

\section{New reference values for forced spirometry in white adults in Brazil*

\author{
Carlos Alberto de Castro Pereira ${ }^{1}$, Taeko Sato ${ }^{2}$, Sílvia Carla Rodrigues ${ }^{3}$
}

\begin{abstract}
Objective: To describe spirometric reference equations for healthy Brazilian adults who have never smoked and to compare the predicted values with those derived in 1992. Methods: Reference equations for spirometry were derived in 270 men and 373 women living in eight cities in Brazil. Ages ranged from 20 to 85 years in women and from 26 to 86 years in men. Spirometry examinations followed the recommendations of the Brazilian Thoracic Society. Lower limits were derived by the analysis of the fifth percentiles of the residuals.

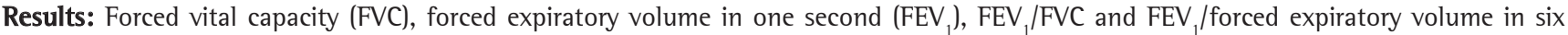
seconds $\left(\mathrm{FEV}_{6}\right.$ ) were best fitted by linear regression. Flows were best fitted using log equations. For both genders, greater height resulted in lower values for $\mathrm{FEV}_{1} / \mathrm{FVC}, \mathrm{FEV}_{1} / \mathrm{FEV}_{6}$ and flow/FVC ratios. The reference values for $\mathrm{FEV}_{1}$ and $\mathrm{FVC}$ in the present study were higher than those derived for Brazilian adults in 1992. Conclusion: New predicted values for forced spirometry were obtained in a sample of white Brazilians. The values are greater than those obtained in 1992, probably due to technical factors.
\end{abstract}

Keywords: Spirometry; Reference Values; Respiratory Function Tests.

\footnotetext{
* Study conducted at the Hospital do Servidor Público Estadual - HSPE, Hospital for State Civil Servants - São Paulo (SP) Brazil.

1. Director of the Service of Pulmonology Department, Hospital do Servidor Público Estadual - HSPE - São Paulo (SP) Brazil.

2. Biochemist. Sanatorinhos Clinical Laboratory, São Paulo (SP) Brazil.

3. Head of the Pulmonary Function Department. Hospital do Servidor Público Estadual - HSPE, Hospital for State Civil Servants - São Paulo (SP) Brazil.

Correspondence to: Carlos Alberto de Castro Pereira. Av. Irai, 393, conj. 34, Moema, CEP 04082-001, São Paulo, SP, Brasil.

Tel 5511 5543-8070. Fax 5511 5044-8716. E-mail: pereirac@uol.com.br

Submitted: 15 August 2006. Accepted, after review: 17 October 2006.
} 


\section{Introduction}

Many pulmonary function laboratories use predictive values without knowing or understanding their derivations and limitations, or by selecting what seems to be the best set of equations. Several equations for reference values have been published in recent decades. Values derived from these equations for a given combination of age and height vary considerably, especially among different populations. ${ }^{(1-3)}$ In addition, predictive values change over time in a determined population.

In Brazil, spirometric reference values in the adult population were obtained for white individuals in 1992. ${ }^{(4)}$ Predicted values for volume-time curves were obtained using bellows spirometers. In the past years, flow spirometers have become highly accurate and are currently the most widely used. A new parameter for the detection of airflow obstruction, the ratio between forced expired volume in one second and forced expired volume in six seconds $\left(\mathrm{FEV}_{1} / \mathrm{FEV}_{6}\right)$, has been suggested. ${ }^{(5)}$ There are no reference values available for this ratio in Brazilians.

The objectives of the present study were to derive reference values for several parameters of the forced expiratory curve, including instantaneous flows and the $\mathrm{FEV}_{1} / \mathrm{FEV}_{6}$ ratio, and to compare the current predicted values for forced vital capacity (FVC) and FEV , with those derived in 1992. ${ }^{(4)}$

\section{Methods}

\section{Population}

Data were collected from the Respire e Viva (Breath and Live) program. Between April and August of 2004, the Brazilian Thoracic Society (SBPT) in partnership with Boehringer and Pfizer pharmaceutical companies conducted a program for the large-scale detection of chronic obstructive pulmonary disease (COPD) in eight Brazilian cities (Santos, Porto Alegre, Curitiba, Brasília, São Paulo, Rio de Janeiro, Belo Horizonte and Recife). A modified bus was placed in squares, supermarket parking lots and trade centers where people were constantly coming and going. Prior to the tests, a widereaching promotional campaign was conducted in different media.

\section{Inclusion and exclusion criteria}

Volunteers presenting for the test, their companions or passersby were selected for the reference sample. The individuals were selected after responding to a questionnaire based on that of the American Thoracic Society/Division of Lung Diseases. ${ }^{(6)}$

Inclusion criteria were as follows:

- Not presenting respiratory symptoms;

- Not having had influenza or any pulmonary disease in the past seven days;

- Having no history of respiratory conditions that could result in dysfunction, such as tuberculosis or asthma, or of having undergone thoracic surgery. Asthma was characterized as two or more wheezing episodes relieved by bronchodilators at any time in life. Individuals with history of pneumonia were not excluded;

- Not having presented physician-diagnosed heart disease at any time in life. Hypertensive individuals were not excluded. Blood pressure was not measured, and the presence or absence of hypertension was only self-reported by the interviewees;

- Not having worked in environments with a high concentration of dust for one year or more, which would be a risk factor; and

- Not being a lifetime nonsmoker. Women who cooked with wood stoves, as well as individuals exposed to cigarette smoke in their bedroom were excluded.

Males over 25 years of age and females over 20 were included in the study. ${ }^{(4)}$ Race was characterized by the interviewer. Black individuals (including mulattos) were excluded because their values were demonstrated to be significantly different from those obtained for white individuals. Asian individuals or individuals born in other countries were also excluded.

\section{Measurements}

Weight and height were measured with the individuals wearing light clothing and barefoot. The age considered was that of the last birthday. Individuals underwent the spirometric test in the sitting position, wearing a nose clip. Three fixed techniques validated by SBPT or by the authors were used for the tests. The tests were performed with Multispiro 
spirometers (Creative Biomedics, San Clemente, CA, USA).

Criteria for curve acceptability were those proposed by SBPT ${ }^{(7)}$

During the FVC maneuvers, real-time graphs of the flow-volume and volume-time curves were provided, with a signal indicating acceptance of end-of-test criteria. In the equipment used, the tests automatically superimpose, which makes it easier to determine their reproducibility.

Once the acceptability criteria had been met, the curves were classified according to their reproducibility as:

- Quality A - maximum differences $<150 \mathrm{~mL}$ for FVC and FEV, in the two best curves, and $<10 \%$ for peak expiratory flow (PEF). A total of 572 tests (89\%) achieved quality A; and

- Quality B - maximum differences $<200 \mathrm{~mL}$ for FVC and FEV in the two best curves, and $<15 \%$ for peak expiratory flow (PEF). Tests exceeding these limits were excluded. No difference was found for predicted FVC and FEV , between quality $A$ and $B$ tests, when adjusted for age and height using the analysis of covariance.
Once acceptability and reproducibility criteria were met, the highest FVC, FEV and PEF values were recorded. Flows were derived from the maneuvers with the highest sums of FVC and FEV .

Curves with evidence of resistance and zero errors were excluded. ${ }^{(8)}$ Calibrations prior to each work period were performed with 3-L syringes. All tests were reviewed after the three best curves had been printed.

\section{Strategy for data analysis}

The SPSS-10 software package was used for the analysis of results, according to the following steps:

- Verification of distribution of functional and anthropometric variables and of discrepant values. Individuals with morbid obesity, that is, body mass index (BMl, weight $/$ height $^{2}$ ) $\geq 40 \mathrm{~kg} / \mathrm{m}^{2}$, individuals with $\mathrm{BMl}<18 \mathrm{~kg} / \mathrm{m}^{2}$, as well as those with a discrepant FVC/height ${ }^{2}$ ratio were excluded;

- Univariate regression analysis testing the correlation coefficients of functional parameters with the anthropometric variables and their

Table 1 - Distribution of the male and female reference populations by height, body mass index and age range.

\begin{tabular}{|c|c|c|c|c|}
\hline \multirow[t]{2}{*}{ Variable } & \multicolumn{2}{|c|}{ Males $(\mathrm{n}=270)$} & \multicolumn{2}{|c|}{ Females $(n=373)$} \\
\hline & $\mathrm{n}$ & $(\%)$ & $\mathrm{n}$ & $(\%)$ \\
\hline \multicolumn{5}{|l|}{ Age (years) } \\
\hline 20-24 & - & - & 19 & (5.1) \\
\hline $25-34$ & 51 & $(18.9)$ & 55 & (14.7) \\
\hline $35-44$ & 70 & $(25.9)$ & 73 & (19.6) \\
\hline $45-54$ & 65 & $(24.2)$ & 67 & (18.0) \\
\hline $55-64$ & 39 & $(14.4)$ & 64 & $(17.2)$ \\
\hline $65-74$ & 32 & $(11.8)$ & 74 & (19.8) \\
\hline$\geq 75$ & 13 & $(4.8)$ & 21 & $(5.6)$ \\
\hline \multicolumn{5}{|l|}{ Height (cm) } \\
\hline 135-144 & - & - & 9 & (2.4) \\
\hline $145-154$ & 2 & $(0.7)$ & 122 & (32.7) \\
\hline $155-164$ & 46 & $(17.0)$ & 187 & $(50.1)$ \\
\hline $165-174$ & 144 & (53.3) & 51 & (13.7) \\
\hline $175-184$ & 70 & $(25.9)$ & 4 & $(1.1)$ \\
\hline$\geq 185$ & 8 & (3.1) & - & - \\
\hline \multicolumn{5}{|l|}{ BMl $\left(\mathrm{kg} / \mathrm{m}^{2}\right)$} \\
\hline $18-24$ & 99 & $(36.7)$ & 182 & $(48.8)$ \\
\hline $25-29$ & 145 & (53.7) & 157 & $(42.1)$ \\
\hline $30-37$ & 26 & (9.6) & 34 & (9.1) \\
\hline
\end{tabular}

BMl: Body mass index (weight/height ${ }^{2}$ ). 
transformations. Variables presenting $p<0.10$ were selected for inclusion in the multivariate analysis;

- Discrepant values obtained after calculation of regression equations were detected by standard residuals above 3.3 or below -3.3 standard deviations and by analysis of Mahalanobis distance. ${ }^{(9)}$ To evaluate the influence of discrepant results on regression model results, Cook's distance for the residuals was analyzed. Cases with values above 1 were excluded $^{(9)}$;

- After the multiple regression equations had been determined, the residuals were evaluated and their adherence to the normal curve was graphically verified.

The residuals were plotted against each of the independent variables and against the expected values using the regression equation. If the model is correct, the distribution of residuals should be uniform around the horizontal axis and should not show any pattern. ${ }^{(10)}$ Finally, we determined whether the residuals are constant across age and height ranges; and

- The lower limits of regressions were calculated using the $5^{\text {th }}$ percentile of the residual ${ }^{(3)}$.

Predicted FEV and FVC values obtained in the present study were compared to those published in 1992 for the Brazilian population. ${ }^{(4)}$

The influence that some of the variables evaluated in the questionnaire had on FVC and $\mathrm{FEV}_{1}$ was analyzed using analysis of covariance, taking into account gender, age, height and weight.

The level of significance was set at $p<0.05$.

\section{Results}

A total of 643 white individuals were included in the final analysis. Of those, 373 were females and 270 were males. Distribution of anthropometric data is shown in Table 1. The mean values and dispersion of mean values for spirometric data are shown in Table 2.

Approximately $9 \%$ of individuals of both genders were obese. Exertional dyspnea, altitude of the places where the tests were performed and previous pneumonia did not influence FVC and $\mathrm{FEV}_{1}$ values. Hypertensive individuals had lower values of FVC ( $150 \mathrm{~mL}$ on average, $p=0.003)$ and $\mathrm{FEV}_{1}(90 \mathrm{~mL}, \mathrm{p}=0.034)$ in comparison with nonhypertensive individuals, regardless of weight (analysis of covariance).

The values of $\mathrm{FEV}_{1}, \mathrm{FVC}$ and $\mathrm{FEV}_{6}$, as well as their relationships, were best fitted by linear equations, whereas flows and their relationships with FVC were best fitted by logarithmic equations. Prediction equations are shown in Table 3 for males and in Table 4 for females. Several findings are noteworthy. Weight influenced predicted FVC, $\mathrm{FEV}_{1}$ and $\mathrm{FEV}_{6}$ values in males, but not in females. Predicted values with and without the addition of weight to the equations in males are shown in Table 3. Height negatively influenced predicted

Table 2 - Principal spirometric data of the reference sample.

\begin{tabular}{lcc}
\hline & $\begin{array}{c}\text { Males }(\mathrm{n}=270) \\
\text { mean } \pm \mathrm{SD}\end{array}$ & $\begin{array}{c}\text { Females }(\mathrm{n}=373) \\
\text { mean } \pm \mathrm{SD}\end{array}$ \\
\hline $\mathrm{FVC}(\mathrm{L})$ & $4.64 \pm 0.77$ & $3.14 \pm 0.65$ \\
$\mathrm{FEV}_{6}(\mathrm{~L})$ & $4.51 \pm 0.78$ & $3.11 \pm 0.65$ \\
$\mathrm{FEV}_{1}(\mathrm{~L})$ & $3.77 \pm 0.67$ & $2.56 \pm 0.57$ \\
$\mathrm{FEV}_{1} / \mathrm{FVC}(\%)$ & $81 \pm 5$ & $81 \pm 5$ \\
$\mathrm{FEV}_{1} / \mathrm{FEV}_{6}(\%)$ & $82 \pm 5$ & $82 \pm 5$ \\
$\mathrm{FEF}_{25-75}(\mathrm{~L} / \mathrm{s})$ & $3.87 \pm 1.20$ & $2.70 \pm 0.94$ \\
$\mathrm{FEF}_{50}(\mathrm{~L} / \mathrm{s})$ & $4.82 \pm 1.44$ & $3.40 \pm 1.14$ \\
$\mathrm{FEF}_{75-85}(\mathrm{~L} / \mathrm{s})$ & $1.02 \pm 0.46$ & $0.71 \pm 0.39$ \\
$\mathrm{FEF}_{75}(\mathrm{~L} / \mathrm{s})$ & $1.58 \pm 0.64$ & $1.07 \pm 0.52$ \\
$\mathrm{PEF}^{(\mathrm{L} / \mathrm{s})}$ & $11.1 \pm 1.75$ & $7.14 \pm 1.28$ \\
\hline
\end{tabular}

SD: standard deviation; $\mathrm{FEV}_{6}$ : forced expiratory volume in six seconds; $\mathrm{FEV}_{1}$ : forced expiratory volume in one second; $\mathrm{FEF}_{25-75 \%}$ : forced expiratory flow between 25 and $75 \% ; \mathrm{FEF}_{500 \%}$ : forced expiratory flow at 50\%; $\mathrm{FEF}_{75-850 \%}$ : forced expiratory flow between 75 and $85 \%$; and $\mathrm{FEF}_{750 \%}$ : and forced expiratory flow at $75 \%$. 
values for the $\mathrm{FEV}_{1} / \mathrm{FVC}, \mathrm{FEV}_{1} / \mathrm{FEV}_{6}$ and flows/FVC ratios in both genders.

Values of coefficients of determination $\left(r^{2}\right)$ were generally higher in females; coefficients of determination were higher for FVC and $\mathrm{FEV}_{1}$ in comparison to those obtained for expiratory flows. As regards age, $\mathrm{FEV}_{1}$, on average, drops $26 \mathrm{~mL} /$ year in males and $20 \mathrm{~mL} / \mathrm{year}$ in females. The lower limits of mid- and end-expiratory flow parameters and their relationships with FVC are typically approximately 50 to $60 \%$. End-expiratory flows (forced expiratory flow at $75 \%$ and forced expiratory flow between 75 and 85\%) presented higher $\mathrm{r}^{2}$ values in comparison with the flows derived from the middle of the expiratory curve.

As a general rule, the lower limit for $\mathrm{FEV}_{1} / \mathrm{CVF}$ ratio can be set by subtracting 8 from the predicted value in both genders. The lower limit of 70\% is, on average, reached at 65 years of age for males and at 70 years of age for females.

The comparison between the predicted FVC and FEV 1 values derived in 1992 and the current values is shown in Figure 1. The current equation resulted in values systematically higher for FVC and FEV in both genders (paired t-test $p<0.01$ ). For males, the mean differences for FVC and FEV, were $0.26 \pm 0.11 \mathrm{~L}$ and $0.21 \pm 0.17 \mathrm{~L}$, respectively, compared with $0.12 \pm 0.04 \mathrm{~L}$ and $0.086 \pm 0.024 \mathrm{~L}$, respectively, for females.

\section{Discussion}

In the present study, new reference values for forced spirometry in white adults were derived for
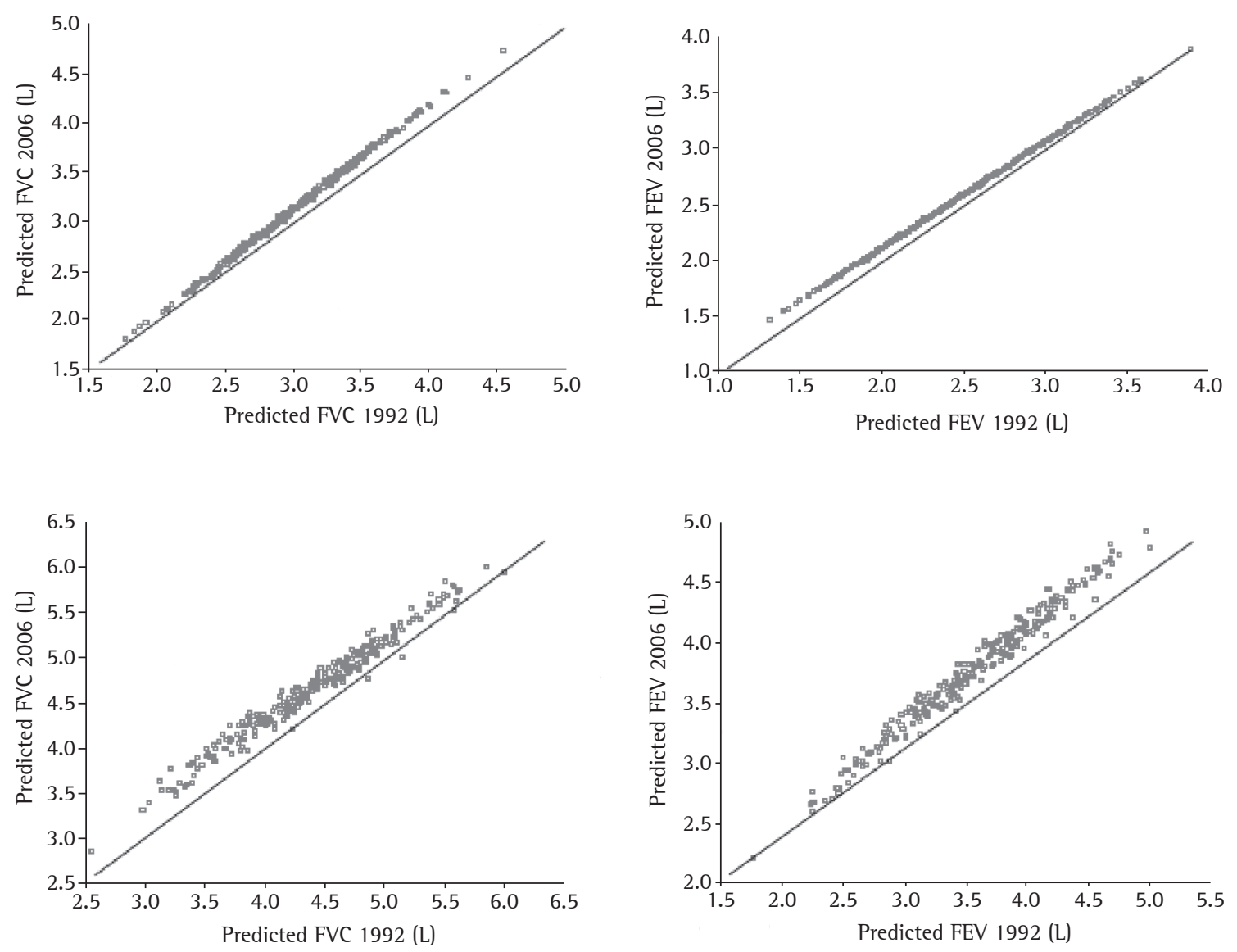

Figure $\mathbf{1}$ - Comparison of the predictive values published in 1992 and 2006 for FVC and FEV in the Brazilian population for females (above) and males (below). 
Table 3 - Regression equations, coefficient of determination $\left(\mathrm{r}^{2}\right)$ and lower limits for spirometric variables in the male reference population.

\begin{tabular}{|c|c|c|c|c|c|c|c|}
\hline Type of equation & $\begin{array}{l}\text { Height } \\
\text { coeffic. }\end{array}$ & $\begin{array}{l}\text { Age } \\
\text { coeffic. }\end{array}$ & $\begin{array}{l}\text { Weight } \\
\text { coeff. }\end{array}$ & Constant & $\begin{array}{c}\text { Adjusted } \\
r^{2} \\
\end{array}$ & $\begin{array}{c}\text { 5th percentile } \\
\text { Residual (abs. or mean) }\end{array}$ & $\begin{array}{l}\text { Lower } \\
\text { limit }\end{array}$ \\
\hline \multicolumn{8}{|l|}{ Linear } \\
\hline FVC (L) & 0.0517 & -0.0207 & - & -3.18 & 0.50 & 0.90 & $P-0.90$ \\
\hline $\mathrm{FEV}_{6}(\mathrm{~L})$ & 0.0521 & -0.0229 & - & -3.179 & 0.53 & 0.87 & $P-0.87$ \\
\hline $\mathrm{FEV}_{1}(\mathrm{~L})$ & 0.0338 & -0.0252 & - & -0.789 & 0.56 & 0.76 & $P-0.76$ \\
\hline FVC (L) & 0.0599 & -0.0213 & -0.0106 & -3.748 & 0.52 & 0.91 & $P-0.91$ \\
\hline $\mathrm{FEV}_{6}(\mathrm{~L})$ & 0.0593 & -0.0235 & -0.00964 & -3.655 & 0.54 & 0.89 & $P-0.89$ \\
\hline $\mathrm{FEV}_{1}(\mathrm{~L})$ & 0.0398 & -0.0257 & -0.0077 & -1.201 & 0.56 & 0.76 & $P-0.76$ \\
\hline $\mathrm{FEV}_{1} / \mathrm{FVC}(\%)$ & -0.175 & -0.197 & - & 120.3 & 0.24 & 7.6 & $P-7.6$ \\
\hline $\mathrm{FEV}_{1} / \mathrm{FEV}_{6}(\%)$ & -0.165 & -0.151 & - & 117.1 & 0.18 & 6.9 & $P-6.9$ \\
\hline \multicolumn{8}{|l|}{ Logarithmic } \\
\hline PEF (L/s) & 0.830 & -0.114 & - & -1.43 & 0.11 & 2.68 & $P \times 0.76$ \\
\hline $\mathrm{FEF}_{50}(\mathrm{~L} / \mathrm{s})$ & - & -0.529 & - & 3.55 & 0.24 & 1.84 & $P \times 0.60$ \\
\hline $\mathrm{FEF}_{75}(\mathrm{~L} / \mathrm{s})$ & - & -1.071 & - & 4.46 & 0.47 & 0.57 & $P \times 0.60$ \\
\hline $\mathrm{FEF}_{25-75}(\mathrm{~L} / \mathrm{s})$ & - & -0.687 & - & 3.93 & 0.34 & 1.50 & $P \times 0.59$ \\
\hline $\mathrm{FEF}_{75-85}(\mathrm{~L} / \mathrm{s})$ & - & -1.169 & - & 4.39 & 0.50 & 0.46 & $P \times 0.58$ \\
\hline $\mathrm{FEF}_{50} / \mathrm{FVC}(\%)$ & -1.827 & -0.307 & - & 15.17 & 0.10 & $36 \%$ & $P \times 0.64$ \\
\hline $\mathrm{FEF}_{75} / \mathrm{FVC}(\%)$ & -1.434 & -0.828 & - & 13.99 & 0.33 & $28 \%$ & $P \times 0.59$ \\
\hline $\mathrm{FEF}_{25-75} / \mathrm{FVC}(\%)$ & -1.609 & -0.454 & - & 14.39 & 0.18 & $29 \%$ & $P \times 0.64$ \\
\hline $\mathrm{FEF}_{75-85} / \mathrm{FVC}(\%)$ & -1.212 & -0.923 & - & 12.76 & 0.37 & $8 \%$ & $\mathrm{P} \times 0.58$ \\
\hline
\end{tabular}

Linear equations: Height $\times$ coefficient - age $\times$ coefficient - weight $\times$ coefficient \pm constant, Example: FVC $=$ height $\times 0.0599$ -age $\times 0.0213$ - weight $\times 0.0106$ - 3.748; Logarithmic equations: natural $\log$ (log height $\times$ coefficient $-\log$ age $\times$ coefficient \pm constant), Example: $\mathrm{PEF}=2.7183^{(\log n \text { height } \times 0.83-\log n \text { age } \times 0.114-1.432)} ; \mathrm{FVC}$ : forced vital capacity; FEV : forced expiratory volume in six seconds; FEV ${ }_{1}$ forced expiratory volume in one second; $\mathrm{FEF}_{25-750}$ : forced expiratory flow between 25 and $75 \%$; $\mathrm{FEF}_{75-85}$ : forced expiratory flow between 75 and 85\% of FVC; PEF: peak expiratory flow; $\mathrm{FEF}_{50 \%}$ : forced expiratory flow at 50\% of FVC; $\mathrm{FEF}_{75 \%}$ : expiratory flow after 75\% of exhalation of FVC; and P: Predicted.

the Brazilian population. These values were significantly higher than those published 14 years ago for both genders.

\section{General considerations}

The reference values published for pulmonary function vary widely. ${ }^{(1-3)}$. The comparison of a small number of normal individuals to find an approximate equation can be misleading. ${ }^{(11,12)}$

Reference values are obtained from a population sample. Five variables must be considered: sample selection; anthropometric variables; diverse variables; test selection/measurement instrument; and regression models.

\section{Sample selection}

For derivation of reference values for pulmonary function, only nonsmokers with no cardiorespiratory symptoms or diseases should be included. ${ }^{(6)} \mathrm{A}$ validated epidemiological respiratory questionnaire should be administered. In addition, the way in which the chosen test is performed and analyzed should be described in detail. ${ }^{(13)}$

Optimal samples are composed of individuals randomly chosen from the general population. The fact that volunteers were enrolled in the present study might have introduced a selection bias. Since the program was widely advertised in advance, individuals from different social classes and from distant locales reported for tests. In addition, many individuals included were companions or occasional passersby. As long as the conditions mentioned above are met, the use of volunteers is a valid means of setting reference values. ${ }^{(13)}$

\section{Anthropometric variables}

Reference values should not be extrapolated for ages and heights other than those included in the 
Table 4 - Regression equations, coefficient of determination $\left(\mathrm{r}^{2}\right)$ and lower limits for spirometric variables in the female reference population.

\begin{tabular}{|c|c|c|c|c|c|c|}
\hline \multicolumn{7}{|c|}{ Females, 20-85 years, height $137-182 \mathrm{~cm}$, white ethnic $(\mathrm{n}=373)$} \\
\hline Type of equation & $\begin{array}{l}\text { Height } \\
\text { coeffic. }\end{array}$ & $\begin{array}{l}\text { Age } \\
\text { coeffic. }\end{array}$ & Constant & Adjusted $r^{2}$ & $\begin{array}{l}\text { 5th residual percentile } \\
\text { (abs. or mean) }\end{array}$ & Lower limit \\
\hline \multicolumn{7}{|l|}{ Linear } \\
\hline FVC (L) & 0.0441 & -0.0189 & -2.848 & 0.66 & 0.64 & $P-0.64$ \\
\hline $\mathrm{FEV}_{6}(\mathrm{~L})$ & 0.0437 & -0.0196 & -2.769 & 0.68 & 0.53 & $P-0.63$ \\
\hline $\mathrm{FEV}_{1}(\mathrm{~L})$ & 0.0314 & -0.0203 & -1.353 & 0.66 & 0.61 & $P-0.61$ \\
\hline $\mathrm{FEV}_{1} / \mathrm{FVC}(\%)$ & -0.140 & -0.158 & 111.5 & 0.17 & -8.5 & $P-8.50$ \\
\hline $\mathrm{FEV}_{1} / \mathrm{FEV}_{6}(\%)$ & -0.107 & -0.141 & 105.9 & 0.16 & -7.9 & $P-7.90$ \\
\hline \multicolumn{7}{|l|}{ Logarithmic } \\
\hline PEF (L/s) & 1.442 & -0.125 & -4.863 & 0.24 & 1.76 & $P \times 0.75$ \\
\hline $\mathrm{FEF}_{50}(\mathrm{~L} / \mathrm{s})$ & 0.839 & -0.044 & -1.369 & 0.23 & 1.41 & $P \times 0.56$ \\
\hline $\mathrm{FEF}_{75}(\mathrm{~L} / \mathrm{s})$ & 1.097 & -0.952 & -1.922 & 0.49 & 0.49 & $P \times 0.53$ \\
\hline $\mathrm{FEF}_{25-75}(\mathrm{~L} / \mathrm{s})$ & 0.998 & -0.588 & -1.852 & 0.36 & 1.09 & $P \times 0.57$ \\
\hline $\mathrm{FEF}_{75-85}(\mathrm{~L} / \mathrm{s})$ & 1.382 & -1.089 & -3.279 & 0.57 & 0.29 & $P \times 0.52$ \\
\hline $\mathrm{FEF}_{50} / \mathrm{FVC}(\%)$ & -1.56 & -0.175 & 13.21 & 0.05 & $41 \%$ & $P \times 0.60$ \\
\hline $\mathrm{FEF}_{75} / \mathrm{FVC}(\%)$ & -1.303 & -0.683 & 12.66 & 0.28 & $14 \%$ & $P \times 0.56$ \\
\hline $\mathrm{FEF}_{25-75} / \mathrm{FVC}(\%)$ & -1.401 & -0.319 & 12.73 & 0.11 & $32 \%$ & $P \times 0.61$ \\
\hline $\mathrm{FEF}_{75-85} / \mathrm{FVC}(\%)$ & -1.02 & -0.819 & 11.30 & 0.37 & $8.6 \%$ & $P \times 0.57$ \\
\hline
\end{tabular}

FVC: forced vital capacity; $\mathrm{FEV}_{6}$ : forced expiratory volume in six seconds; $\mathrm{FEV}_{1}$ : forced expiratory volume in one second; $\mathrm{FEF}_{25-75 \%}$ : forced expiratory flow between 25 and 75\%; $\mathrm{FEF}_{75-85}$ : forced expiratory flow between 75 and 85\% of FVC; PEF: Peak Expiratory Flow; $\mathrm{FEF}_{50 \%}$ : forced expiratory flow at 50\% of FVC; $\mathrm{FEF}_{750 \%}$ : expiratory flow after 75\% of exhalation of FVC; and P: Predicted. Note: for equation derivation see footnote of Table 3.

regression equations. ${ }^{(7)}$ Individuals of both genders and with height and age greater than those of the individuals studied in 1992 were included in the present study. ${ }^{(4)}$ It is well known that there is a trend toward greater height and greater life expectancy among Brazilians. ${ }^{(14,15)}$

The prevalence of obesity in Brazil is approximately $10 \%$ and is higher among females. ${ }^{(16)}$ The effect of obesity on spirometry and pulmonary volumes is influenced by the degree of obesity, age, and type of fat distribution. ${ }^{(17)}$ Morbid obesity has an evident effect on ventilatory function, ${ }^{(18)}$ and weight loss results in increased $\mathrm{FVC}^{(19)}$ in obese individuals, which is why such individuals were excluded. The effect that obesity other than morbid obesity has on spirometry is controversial. ${ }^{(17)}$ Weight can influence FVC values by means of opposite effects - because of increased muscularity, with FVC elevation, and because of obesity, with reduced pulmonary ventilation. In the present study, reduced FVC and FEV, were found in males as weight increased. This was not observed in females. The difference between genders might be attributable to the different obesity patterns - an abdominal pattern in males, which more significantly affects the ventilatory capacity, ${ }^{(20)}$ and a peripheral pattern in females. One recent study ${ }^{(21)}$ showed that abdominal fat can negatively influence pulmonary function even in individuals who are only overweight (not classified as obese). The importance of weight influence on FVC in males can be demonstrated by deriving predicted values for BMl values of 20 and $30 \mathrm{~kg} / \mathrm{m}^{2}$ in a male individual with a height and mean age similar to those observed in the present study. A 0.30-L reduction in FVC is expected in individuals with a BMl of $30 \mathrm{~kg} / \mathrm{m}^{2}$ in comparison to individuals with a BMl of $20 \mathrm{~kg} / \mathrm{m}^{2}$.

\section{Diverse variables}

Lower values of $\mathrm{FVC}$ and $\mathrm{FEV}_{1}$ in hypertensive individuals regardless of their body weight was a new finding. One small study ${ }^{(22)}$ showed lower FVC and FEV ${ }_{1}$ values in untreated hypertensive individuals in comparison to a control group, and this was attributed to a diastolic dysfunction. Further studies should consider the possible influence of hypertension on spirometry. 


\section{Measurement instrument and test selection}

The tests were performed with a flow spirometer that meets the requirements of the American Thoracic Society for precision and accuracy. However, this does not ensure exact tests. Two errors in particular should be observed ${ }^{(8)}$ : the zero error and the resistance error. Flow spirometers need to be zeroed prior to each exhalation. During zeroing, the pressure drop corresponding to the absence of flow is set, thus determining the intercept of the calibration curve that relates flow to the pressure drop. Errors occur when the transducer or the electronic sign measures a false value for the pressure gradient in the absence of flow. As a result, the calibration curve is displaced, so that all flows and volumes will be falsely elevated. This error results in a continuous FVC increase, even if exhalation ends. These curves were excluded.

Debris, condensed water vapor or mucus deposition on the sensor can increase the pressure gradient and result in high flows and volumes after integration (resistance error). Tests with peak flows above $14 \mathrm{~L} / \mathrm{s}$ in males and $11 \mathrm{~L} / \mathrm{s}$ in females were excluded, as were those in which the spirometer-measured PEF exceeded the 95\% limit of the regression plotted against the values obtained with a portable meter.

The American Thoracic Society and the European Respiratory Society do not recommend the use of peak flow as a criterion of reproducibility of spirometric curves. ${ }^{(23)}$ However, submaximal effort (resulting in lower PEF values) can increase FEV, due to lower airway compression ${ }^{(24)}$. In this study, we also observed that a late PEF (beyond $0.5 \mathrm{~s}$ ) can result in higher FVC. The two best curves should differ by $<15 \%$ for PEF. Absolute differences between the highest PEF values should not be used for exclusion or inclusion of curves. ${ }^{(25)}$

Although $\mathrm{FEV}_{1} / \mathrm{FVC}$ ratio values $<70 \%$ are used to characterize COPD, ${ }^{(26)}$ a single value is inappropriate, since the lower limit varies with age. A fixed cut-off point results in overdiagnosis in the elderly and underdiagnosis of COPD in middle-aged individuals, in whom early diagnosis is essential. ${ }^{(27)}$

Taller individuals can present falsely reduced $\mathrm{FEV}_{1} / \mathrm{FVC}$ ratio values due to enhanced expiratory muscle force generation and subsequent airway compression. ${ }^{(7)}$ The finding of a negative correlation between height and $\mathrm{FEV}_{1} / \mathrm{FVC}$ and flows/FVC ratios expresses this phenomenon so that the physiological effect of greater height can be distinguished from the presence of an occasional obstructive disease.

As observed in Tables 3 and 4, end flows and their relationship with FVC had coefficients of determination well above those observed for flows derived from the middle of the expiratory curve. Further studies are necessary in order to compare the relative value of mid-and end-expiratory flows in the diagnosis of airflow limitation.

\section{Regression models}

The choice of the best regression model should follow several steps, and linear equations should be preferred whenever the adjustment is similar to other models, because of their simplicity. If functional decline increases with age, linear models can overestimate the predicted values in younger individuals as well as in the elderly. However, derivation of predicted values from the general equation in certain age ranges did not show significant errors. As in the 1992 study, ${ }^{(4)}$ flow equations followed a logarithmic curve. Due to the acceleration of functional loss with aging, some authors include a quadratic term for age. ${ }^{(25)}$ However, this resulted in very low predictive values in advanced ages and in inhomogeneous distribution of residuals around the regression curve.

\section{Comparison with the 1992 equation}

Functional values change with time as a result of changes in environmental and nutritional conditions and because of technological advances in equipment and higher accuracy in measurements (cohort effect). Reference values should be periodically obtained. Otherwise, a loss of sensitivity in the detection of abnormal conditions will occur. Values of FVC and FEV 1 were higher than those observed 14 years prior. ${ }^{(4)}$ Cohort effects, however, do not fully explain these findings. Due to the cohort effect, ${ }^{(28)}$ $\mathrm{FVC}$ and $\mathrm{FEV}_{1}$ can increase up to $5 \mathrm{~mL} / \mathrm{year}$, and the difference observed for FVC between the previous and the current study was three times greater in males.

Differences in measurement instruments and in populations contribute to the variation in pulmonary function. However it is difficult to quantify each of these factors. Subject selection and the epidemiological questionnaire administered were similar in both studies. In the previous study, a 
vertical bellows spirometer was used, and in the current study, a flow spirometer. Vertical bellows spirometers can be affected by gravity. Bellows compliance is temperature dependent, which can affect accuracy and precision. With multiple exhalations into the bellows, the pleats can become moist and sticky, so that they do not open uniformly, and this can result in nonlinearity. Old bellows can tear along the pleats, and this can go unnoticed in a 3-L syringe test. ${ }^{(29)}$ Among the various types of spirometers, vertical bellows spirometers present the greatest resistance at low flows.

Spirometers have gone through significant changes in recent years. Immediate information on acceptability and reproducibility criteria makes the technician demand optimal efforts and, therefore, obtain maximum values. It is no wonder that current values exceed those obtained 14 years ago with bellows spirometers. The FVC and FEV, values were proportionally higher, and the $\mathrm{FEV}_{1} / \mathrm{FVC}$ ratio remained unchanged. Some authors ${ }^{(30)}$ have found that the values obtained with vertical bellows spirometers are lower than those obtained with other spirometers.

In conclusion, new predicted spirometry values were obtained in a broad sample of the Brazilian population. These values were higher than those published in 1992, which likely results from technical factors. Values for the $\mathrm{FEV}_{1} / \mathrm{FEV}_{6}$ ratio and for instantaneous flows are now also available.

\section{References}

1. Roca J, Burgos F, Sunyer J, Saez M, Chinn S, Antó JM, et al. References values for forced spirometry. Group of the European Community Respiratory Health Survey. Eur Respir J. 1998;11(6):1354-62.

2. Baur X, lsringhausen-Bley S, Degens P. Comparison of lungfunction reference values. Int Arch Occup Environ Health. 1999;72(2):69-83.

3. Lung function testing: selection of reference values and interpretative strategies. American Thoracic Society. Am Rev Respir Dis. 1991;144(5):1202-18.

4. Pereira CAC, Barreto SP, Simões JG, Pereira FWL, Gerstler JG, Nakatani J. Valores de referência para espirometria em uma amostra da população brasileira adulta. J Pneumol. 1992;18(1):10-22.

5. Hankinson JL, Odencrantz JR, Fedan KB. Spirometric reference values from a sample of the general U.S. population. Am J Respir Crit Care Med. 1999;159(1):179-87.

6. Ferris BG. Epidemiology Standardization Project (American Thoracic Society). Am Rev Respir Dis. 1978;118(6 Pt 2):1-120.

7. Sociedade Brasileira de Pneumologia. Diretrizes para Testes de Função Pulmonar. J Pneumol 2002;28(supl 3):1-82.
8. Townsend MC, Hankinson JL, Lindesmith LA, Slivka WA, Stiver G, Ayres GT. ls my lung function really that good? Flow-type spirometer problems that elevate test results. Chest. 2004;125(5):1902-9.

9. Pallant J. Multiple regression. In: Pallant J. SPSS. Survival manual. $2^{\circ}$ ed. Berkshire: Open University Press; 2005. p. $140-59$.

10. Campbell MJ. Multiple regression. In: Campbell MJ. Statistics at Square Two: Understanding modern statistical applications in medicine. London: Blackwell Publishing; 2004. p.16-23

11. Dias RM. Análise das equações para previsão de valores espirográficos normais. J Pneumol. 1990;16(4):206-11.

12. Ladosky W, Andrade RT, Loureiro NG, Gandar JMB, Botelho MM. Comparação entre valores espirométricos de referência obtidos a partir de equações de Knudson e de Pereira Adultos. J Pneumol. 2001;27(6):315-20

13. Grasbeck R. The evolution of the reference value concept. Clin Chem Lab Med. 2004;42(7):692-7.

14. IBGE - Instituto Brasileiro de Geografia e Estatistica [Homepage on the Internet]. Brasília: Ministério do Planejamento, Orçamento e Gestão. [cited 2006 Aug 15]. Pesquisa de orçamento familiares 2002-2003 - microdadossegunda divulgação. Available from: www.ibge.gov.br

15. IBGE - Instituto Brasileiro de Geografia e Estatistica [Homepage on the Internet]. Brasília: Ministério do Planejamento, Orçamento e Gestão. [cited 2006 Aug 15]. Tábuas completas de mortalidade-2003. Available from: www.ibge.gov.br

16. Batista Filho M, Rissin A. Nutritional transition in Brazil: geographic and temporal trends. Cad Saude Publica. 2003;19(Suppl 1):S181-91

17. Koenig SM. Pulmonary complications of obesity. Am J Med Sci. 2001;321(4):249-79.

18. Ladosky W, Botelho MA, Albuquerque JP. Chest mechanics in morbidly obese non-hypoventilated patients. Respir Med. 2001;95(4):281-6

19. Wadstrom C, Muller-Suur R, Backman L. Influence of excessive weight loss on respiratory function. A study of obese patients following gastroplasty. Eur J Surg. 1991;157(5):341-6

20. Lazarus R, Sparrow D, Weiss ST. Effects of obesity and fat distribution on ventilatory function: the normative aging study. Chest. 1997;111(4):891-8

21. Ochs-Balcom HM, Grant BJ, Muti P, Sempos CT, Freudenheim JL, Trevisan M, et al. Pulmonary function and abdominal adiposity in the general population. Chest. 2006;129(4):853-62.

22. Guven A, Koksal N, Sokmen G, Ozdemir R. Comparison of the echocardiographic and pulmonary function test findings in orderly treated and untreated essential hypertensive patients. Blood Press. 2003;12(5-6):319-25

23. Miller MR, Hankinson J, Brusasco V, Burgos F, Casaburi R, Coates R, et al. Standardisation of spirometry. Eur Respir J. 2005; 26(2): 319-38

24. Krowka MJ, Enright PL, Rodarte J, Hyatt RE. Effect of effort on measurement of forced expiratory volume in one second. Am Rev Respir Dis. 1987;136(4):829-33.

25. Bravo de Souza R, Martins AC, Azevedo KRS, Pereira VMF. Avaliação de critérios de rejeição de curvas de capacidade vital forçada. J Pneumol 2002; 28 (supl 2):11-12.

26. Pauwels RA, Buist AS, Calverley PM, Jenkins CR, Hurd SS; GOLD Scientific Committee. Global strategy for the diagnosis, management, and prevention of chronic obstructive pulmonary disease: NHLBI/WHO Global Initiative for Chronic 
Obstructive lung Disease (GOLD) Workshop summary. Am J Respir Crit Care Med. 2001;163(5):1256-76

27. Hardie JA, Buist AS, Vollmer WM, Ellingsen I, Bakke PS, Mørkve 0, et al. Risk of over-diagnosis of COPD in asymptomatic elderly never-smokers. Eur Respir J. 2002;20 (5): $1117-22$

28. Xu X, Laird N, Dockery DW, Schouten JP, Rijcken B, Weiss ST. Age, period, and cohort effects on pulmonary function in a 24-year longitudinal study. Am J Epidemiol. 1995;141(6):554-66.

29. Branson R. Flow and Volume Measuring Devices. In: Branson RD, Hess DR, Chatburn RL, editors. Respiratory Care Equipment. Philadelphia: Lippincott Williams \& Wilkins; 1998. p. 283-303.

30. Louw SJ, Goldin JG, Joubert G. Spirometry of healthy adult South African men. Part 1. Normative values. S Afr Med J. 1996;86(7):814-9 